\title{
Globalization and the Human Development Trap
}

\author{
David Mayer-Foulkes*
}

October 2007

\begin{abstract}
The feeble results of liberalization policies in Latin America are explained in terms of a multiple steady state model including a dynamic human development trap, endogenous technological change, technology transfer and trade. Divergent and convergent steady states, with and without a human development trap, exist under both autarchy and free trade. The model explains why import substitution is inferior to export promotion. While globalization is a necessary condition for convergence to development, it is not sufficient. Both trade and foreign direct investment create innovation assymetries hindering lagging countries that need to be balanced with export promotion and technological transfer for their successful integration with the global economy. In addition, so long as the human development trap persists, unskilled and skilled workers will have a conflict of interest between supporting human capital investment and innovation. If only innovation is supported, the human capital trap will persist. If mainly human capital investment is pursued, technology levels will fall behind; switching to innovation will be necessary eventually. The world growth rate is maximized by regulating globalization so as to attain development in all countries.
\end{abstract}

Keywords: trade, investment, technology

JEL classification: O16, O33

\section{Copyright (C) UNU-WIDER 2007}

* Centro de Investigación y Docencia Económicas, CIDE, Mexico. Email: david.mayer@cide.edu

This is a revised version of a paper originally prepared for the UNU-WIDER project conference on The Impact of Globalization on the Poor in Latin America, directed by Professors Machiko Nissanke and Erik Thorbecke. The conference was organized in Rio de Janeiro, in collaboration with Pontifícia Universidade Católica do Rio de Janeiro.

UNU-WIDER gratefully acknowledges the financial contribution of the Finnish Ministry of Foreign Affairs to this project, and the contributions from the governments of Denmark (Royal Ministry of Foreign Affairs), Norway (Royal Ministry of Foreign Affairs), Sweden (Swedish International Development Cooperation Agency_Sida) and the United Kingdom (Department for International Development) to the Institute's overall research programme and activities. 
Figures appear at the end of the paper.

The World Institute for Development Economics Research (WIDER) was established by the United Nations University (UNU) as its first research and training centre and started work in Helsinki, Finland in 1985. The Institute undertakes applied research and policy analysis on structural changes affecting the developing and transitional economies, provides a forum for the advocacy of policies leading to robust, equitable and environmentally sustainable growth, and promotes capacity strengthening and training in the field of economic and social policy making. Work is carried out by staff researchers and visiting scholars in Helsinki and through networks of collaborating scholars and institutions around the world.

www.wider.unu.edu

publications@wider.unu.edu

UNU World Institute for Development Economics Research (UNU-WIDER)

Katajanokanlaituri 6 B, 00160 Helsinki, Finland

Typescript prepared by the author.

The views expressed in this publication are those of the author(s). Publication does not imply endorsement by the Institute or the United Nations University, nor by the programme/project sponsors, of any of the views expressed. 


\section{Introduction}

In the Latin American context, a society-wide reevaluation of globalization is currently underway. The pro-market liberalization policies that have been followed for a decade and a half have been only mildly successful. These policies have essentially followed the Washington Consensus, consisting mainly of opening to trade and foreign direct investment (FDI), maintaining macroeconomic stability, and entrusting economic development to market functioning. These policies were established as a response to the Latin American debt crisis in the 80's, in recognition of the demise of import substitution. The East Asian economies had espoused export promotion and experienced a transition to development. The expectation was that liberalization could put Latin American economies on the same path. Widespread dissatisfaction with the results has shifted economic policies towards government intervention for direct poverty alleviation in a series of countries.

An economic explanation is needed that can answer to this reality. Why was export promotion better than import substitution? Yet, why have the results of liberalization been meager? What role does the high level of inequality in Latin America play? Why do millions not believe in marketguided policies? Why is globalization perceived as unfair? Where to go from here to address the problems of poverty and development? The objective of this chapter is to provide just such an explanation, fully grounded in economic theory. To do so, I combine several important strands of research on economic growth, human development, and the role early child development.

\subsection{Trade, technological change and economic growth}

The first strand of research I draw from is research on economic growth. Over a decade of research has reached the consensus that differences in income per capita between countries are mainly due to differences in technology. ${ }^{1}$ Thus, economic growth is mainly and above all the process through which technological levels of production rise. ${ }^{2}$ Hence to understand the impact of global-

\footnotetext{
${ }^{1}$ See Howitt and Mayer-Foulkes (2005, pages 1-2) for references to studies attributing cross-country differences in per-capita GDP to differences in productivity.

${ }^{2}$ Schumpeterian analysis of endogenous technological change first concentrated on R\&D in developed countries as the source of economic growth (Aghion and Howitt, 1988, 1992) and convergence (Howitt, 2000). It can also explain convergence clubs, underdevelopment and divergence (Howitt and Mayer, 2005; Aghion, Howitt and Mayer-Foulkes, 2005).
} 
ization on economic growth, it is necessary to understand how technological change takes place under trade and FDI.

I address here the question, how does the international allocation of production under trade and FDI, which has been studied extensively, affect the international allocation of innovation $?^{3}$ This question is examined by MayerFoulkes (2006a), who finds that standard trade theory implies the following natural, real, macroeconomic principle ${ }^{4}$ governing the international allocation of innovation under trade. Under trade, the volume of innovative sectors that a country can dominate (and consequently, under certain conditions, its rate of technological change) is proportional, ceteris paribus, to its productive capacity. Suppose that the economy consists of a continuum of sectors, whose production involves distinct technologies and comparative advantages between countries. Lagging economies with low levels of productivity will only be able to cover world demand for a small number of sectors. Hence in lagging economies technological change will be limited to a small set of sectors, implying low returns to investment in technological change, even after taking technology transfer into account. Hence free trade introduces innovation imbalances between countries.

The result is extended to include FDI, a salient feature of globalization both in the 19th and 20th Centuries, in Mayer-Foulkes (2006b). When foreign investors produce abroad to benefit from cheap labor and cheap resources, as their profits rise so do their incentives to innovate. Moreover, innovation in the sectors they occupy in host countries is crowded out by their unassailable competition. Thus FDI generates asymmetric incentives to innovation that favor leading countries and compound the innovation imbalances introduced by trade. Technology transfer from FDI, which can play a very significant role favoring economic growth in the host country, tends to occurs with high enough intensity only under appropriate regulation or negotiation. It follows that development and underdevelopment persist as different steady states under globalization. Both this result and the previous one on trade are strong theoretical results, relying only on the assumptions commonly used in models of trade and of endogenous technological change, and not on assumed asymmetries between countries, which underlie most explanations

\footnotetext{
${ }^{3}$ Innovation is broadly understood to include research and development as well as imitation and technology adoption.

${ }^{4}$ By economic principle I mean a result that can be proved from microeconomic assumptions in a series of contexts, such as the existence of general equilibrium, and the welfare theorems.
} 
of underdevelopment.

These theoretical results can explain the simultaneous historical emergence from stagnation to modern economic growth, and the appearance of underdevelopment, or the Great Divergence (Mayer-Foulkes, 2006a). Development and underdevelopment appeared and were stable, and the Great Divergence proceeded, not only under free trade but also under FDI through the First Great Age of Globalization (approximately from the 1820's to 1914), and up to the present (Mayer-Foulkes, 2006b). The results apply equally well to the present era of globalization, which accelerated since the early 1980's.

Since technological leaders trade, their innovators enjoy global incentives for innovation. Thus steady states for closed economies will be lower. Openness is therefore a necessary condition for development, for all except possibly the largest countries. As a consequence, an import substitution strategy is likely to exhaust itself when technology reaches levels requiring world market incentives for innovation. An export promotion strategy will not hit these limits. But openness is not a sufficient condition for development. Ceteris paribus, under market forces only economies not lagging too far behind converge to the developed steady state. For smaller and more backward countries market forces must be augmented with export promotion and technology adoption to provide enough push for a change of steady state.

\subsection{Human development and economic growth}

The second strand of research I draw from is historical research on the strong, long-term, mutual impact between human development and economic growth. This research attributes about a third of long-term economic growth to improvements in health, that is, to human development. As economic development took place, tremendous changes in human health occurred. Life expectancy and average adult height and weight rose tremendously. ${ }^{5}$ The synergism between technological and physiological improvements has produced a dynamic, long-term, culturally transmitted form of human evolution that is biological but not genetic, called by Fogel (2002) technophysio evolution. The term human development includes here the long-term dimension

\footnotetext{
${ }^{5}$ Average stature rose from 164 to $181 \mathrm{~cm}$ in Holland between 1860 and 2002 and from 161 to $173 \mathrm{~cm}$ in France and Norway between 1705 and 1975. Average weight rose from 46 to $73 \mathrm{~kg}$ in Norway and France, 1705 to 1975. Life expectancy rose from 41 to 78 years in England between 1841 and 1998; and from 29 to 60 years in India between 1930 and 1990. (Fogel, 2002; Cervellati, Matteo and Uwe Sunde, 2003.)
} 
of change.

A third strand of research underlines the intergenerational nature of human development. Microeconomic studies have found that early child development (ECD) is a crucial link in the intergenerational transmission of socioeconomic status and in the adult correlation between health and income. Using the 1958 National Child Development Study, which follows all children born in Great Britain in the week of March 3, 1958, Case, Fertig and Paxson, (2003) find that, controlling for parental income, education and social status, children who experience poor health have significantly lower educational attainment, and significantly lower average adult health and earnings. More specifically, Heckman and Carneiro (2003) identify ECD as a crucial stage of investment in human capital formation, with especially high returns.

Now, it is a commonly accepted fact that investment in human development in general and ECD in particular are characterized by market failures, in so far as the level of these investments depends heavily on parental wealth, rather than on the returns to human capital investment. Thus, from the economic point of view, the investment process sustaining human development is characterized by market failures. Human development can be understood as an intergenerational process of human capital accumulation, slowed by the presence of market failures limiting the necessary investment, in which early child development plays a critical role. ${ }^{6}$

\subsection{Globalization and development}

To analyze the interaction of human development and economic growth under globalization, I construct a human development trap model representing an intergenerational poverty trap in human capital investment, and set it in the context of trade and endogenous technological change.

I first describe the human development trap model in some detail. It is an overlapping generations model in which altruistic parents make their children a bequest. A high enough bequest provides them with the opportunity for an indivisible investment in human capital. In the present context, this investment acquires both skills and the current human development potential. If the bequest is too low, the absence of credit markets makes the investment impossible. The construction closely follows Galor and Zeira's (1993) well

\footnotetext{
${ }^{6}$ For an extensive discussion and references on human development and economic growth, and the role of child development, see Mayer-Foulkes, D. (2007).
} 
known, simple, poverty trap model, building upon it in two ways.

First, the usual assumption of increasing returns to human capital is removed. Instead, investment indivisibilities and the absence of credit markets lead to an undersupply of human capital. Under the assumption that skilled and unskilled labor are complementary, undersupply implies that skills command extraordinary returns, defined as higher returns than the interest rate.

Second, a dynamic trap is defined, which subsists under economic growth. Poverty trap models are usually static and therefore unrealistic in the longterm. Here the trap defines two population classes. One is skilled, attains the current human development potential, and is able to bequeath its children with the next generation's human development potential. The other is unskilled, lives beneath the human development potential, and is unable to bequeath it. Yet both experience income growth as technology rises through time. ${ }^{7}$ At lower levels of development, human capital may be thought to be more intensive in nutrition and health, while at higher levels, successively higher levels of education become a more important component. This combination of inequality and growth is consistent with the extraordinary persistence of within-country inequality, at widely different income levels and growth rates. ${ }^{8}$

I assume that, because of the non-marketable benefits of human development, including lifelong health, knowledge for living and life expectancy, the whole population will opt for human capital investment if given the opportunity. The trap exists if the proportion of unskilled workers is high enough that human capital is undersupplied. If instead the trap disappears and skills become oversupplied, some skilled workers will work at unskilled jobs and the whole population will attain the current human development potential.

Mayer-Foulkes (2007) presents strong evidence for the existence of such a human development trap in contemporary Mexico, including extraordinary returns to education, high returns to ECD, and a multiple-peaked distribution of human capital across households. In fact, extraordinary returns to education, defined as returns significantly higher than OECD levels, exist, on average, throughout the underdeveloped world. ${ }^{9}$ This constitutes evidence

\footnotetext{
${ }^{7}$ Income growth does not make class differences trivial or irrelevant. At a $2 \%$ growth rate, a proportional class income gap of 4 represents a 70 year lag.

${ }^{8}$ As Kanbur (2005) states: "There is no statistical correlation between changes in per capita income and changes in inequality, taking countries as the unit of observation."

${ }^{9}$ See Tables 1 and 2, Psacharopoulos \& Patrinos (2002). For a full discussion see Mayer-Foulkes (2007).
} 
for the existence of a human development poverty trap or prolonged transition (when the poor need several generations to attain the local human development potential) in non-OECD Asia, Latin America and Africa.

The human development trap model is set in the context of trade and endogenous technological change by means of a reduced form expression including the following components. 1) Human capital raises production levels and contributes to technological change by increasing the resources for innovation. 2) Under trade, each sector produces for the global market and has higher resources for innovation. 3) The operation of comparative advantage also increases resources for innovation. 4) The transfer of ideas, which may rise under trade, also contributes to convergence. 5) Specialization under trade implies that the number of productive sectors in each country, where innovation occurs, is proportional to each economy's GDP, once comparative advantage and innovation are taken into account). 6) The productivity of innovation investment in each country is higher when more sectors are involved in innovation. ${ }^{10}$

The result is an analysis of the interaction of multiple steady states across countries in the context of globalization, with the human development trap occurring within countries.

\subsection{Development and Underdevelopment: distinct steady states}

To see how the full model deepens the discussion on human development and economic growth, let us return to the comparison of East Asia and Latin America. Comparing the performance of the two regions, Birdsall, Ross \& Sabot (1997) stress the two-way causality between human capital and inequality, on the one hand, and economic growth on the other. The success of the export-oriented development strategy was more labor and skill demanding. As higher growth was achieved, a higher GDP led to higher investments per pupil, higher educational quality, lower income inequality, and lower absolute levels of poverty. On the other hand, the unequal distribution of the quantity and quality of education in Latin America led to forgone opportu-

\footnotetext{
${ }^{10}$ This assumption is implicit in many models of endogenous technological change. For example, thi occurs when research in a continum of sectors contributes through an externality to raise the leading technological frontier, in turn raising the productivity of innovation investment for all sectors.
} 
nities in labor productivity and economic growth.

The two examples of interaction between economic growth and human development can be explained in two ways by the model. A simple explanation, not resorting to multiple steady states, is simply that policies, such as promoting exports and technology adoption, matter for the success of the productive sector under globalization. When higher rates of technological change are achieved, improvements in production raise the returns to education and the resources available for human capital investment.

A second, deeper explanation is the following. Latin America remained in a lower steady state, with lower returns to human capital, because of its higher levels of initial inequality, and because it followed a strategy of import substitution that not only did not promote trade but also depended on unregulated FDI that crowded out innovation. In contrast, East Asia converged to development. Enjoying lower levels of initial inequality, it followed a careful globalization strategy featuring export promotion and technology adoption, and experienced miracle growth as it changed steady state to become a successful global partner in trade and development, with high returns to human capital. It is worth noting that the larger East Asian countries, Japan, Korea and Taiwan, jealously nurtured their technological independence and avoided dependence on FDI. ${ }^{11,12}$ A change of steady state perspective for East Asia is supported in detail in Wan's (2004) comparative country case studies.

An additional result that emerges from jointly analyzing human development and economic growth is a tension between the policy preferences of the skilled and unskilled. Assume that both human capital investment and innovation require government support. Skilled workers will favor innovation. Increases in productivity will raise the returns to human capital, while extraordinary returns to skills will fall with human capital investment on the unskilled. In contrast, unskilled workers favor human capital investment. This unlocks productive capabilities without the need for technological

\footnotetext{
${ }^{11}$ To the contrary, Singapore, a small country, promoted FDI by consistently underpricing its human capital. Hong Kong's development is based on geographical advantages for trade: an excellent natural harbour ideally situated to serve Pacific and China-West trade.

${ }^{12} \mathrm{An}$ example of innovation crowding out is provided by the automotive industry. Europe and America, original inventors of the automobile, produce, import and export automobiles. Japan and Korea, which did not allow foreign production of automobiles, only produce and export their own brands. In contrast, Latin America, an FDI host in automobiles, did not develop its own automobiles (Table 1, Mayer-Foulkes, 2006b, data from ILO 2000).
} 
change. Under the skilled workers' preferred policies, the human development trap will persist. Under the unskilled workers' preferences, human capital investment will be carried out at the cost of worsening the country's relative technological lag. By entrenching the economy in a lower steady state, this could make emerging from underdevelopment impossible. In addition, once the human capital trap is overcome, government support will have to change its focus to technological change. This may require quite a strong institutional and policy shift, as occurred in the ex-socialist countries. The tension between policies to help the poor (here modeled as human capital investment) and policies for economic growth (here modeled as investment in technological change) is a significant problem in Latin America, as in much of the underdeveloped world. According to the model, both extremes generate inferior policies. However, in practice the two objectives can intersect: generating human capital to support technological change for export promotion is an example of an optimal combination.

What does the model conclude? First, no asymmetric assumptions between countries (for example in geography or institutions) are necessary to show the existence of multiple steady states under globalization - development and underdevelopment. The usual assumptions used in models of trade and endogenous technological change suffice, since they can explain the allocation of production and therefore innovation across countries by trade and FDI. Second, increasing returns in human capital is not a necessary conditions for a human capital poverty trap to exist. It is enough if a large enough portion of families cannot endow their children with human capital - due to incomplete or malfunctioning markets. The ensuing undersupply will lead to extraordinary returns to skills and the population will divide into two classes, whose different living standards will evolve in parallel according to each country's technological level.

When these phenomena - human development, trade and innovation - are analyzed together, multiple steady states in human and technological development emerge that coexist under globalization. At the highest steady states the human development trap has disappeared and high levels of technology are enjoyed. At lower steady states the human development trap may persist and low levels of technology cannot be escaped. A diversity of growth experiences, including the likelihood in underdeveloped countries of pro-rich and pro-poor policy regimes, that is consistent with the true-life physiognomy of development and underdevelopment, results. 


\subsection{Does globalization yield development?}

We now let the model answer the questions that motivated this chapter.

Why was export promotion better than import substitution? Because high level technologies are based on innovations that require world-market incentives. Domestic markets of all but the largest countries cannot hope to support the innovative capacity of leading economies involved in world trade. The purposeful, strategic policies promoting exports and technology adoption that East Asian economies followed, supplied large markets and fed their economic growth.

Why have the results of liberalization been meager? Because globalization, that is, openness to trade and foreign investment, will not automatically lead to development. Success depends on economy size, human resource levels, and on implementing policies promoting exports and technology adoption. Other determinants of aggregate production, such as institutional and financial development, also affect steady state membership.

What role does the high level of inequality in Latin America play? Inequality, representing the presence of a human development trap and low human resource levels, is a determinant of steady state membership. In its presence, and in the absence of policies truly promoting competitive technologies for the global market, development is impossible.

Why do millions not believe in market-guided policies? Because millions of people are subject to an intergenerational poverty trap that exists precisely because it is impervious to market forces. (This and the following statement are consistent with rational expectations.)

Why is globalization perceived as unfair? Because it provokes innovation imbalances and innovation crowding out favoring advanced countries.

Where to go from here? Globalization is a necessary condition for development. But it is not sufficient. What is required is to govern globalization through policies compensating the long-term imbalances it creates, favoring successful integration of weaker economies, promoting technology transfer, encouraging exports from lagging countries, bolstering universal knowledge integration. China has been successful at regulating trade and FDI, to ensure its own growth in the process of integration. To extend such arrangements for mutual benefit to the many smaller countries, global governance and regulation are required. Macroeconomic measures for achieving control and

coordination with the same objectives may exist as well, to be implemented as a part of global governance. 
Furthermore, the trade and innovation model discussed here shows that development is not a zero sum game. Leading countries' welfare depends essentially on the world growth rate, and this is maximized when the world is fully developed. This can only occur when human development is achieved everywhere and every country enjoys its full share of innovation. Concerted nutrition, health, skills, know-how, research and infrastructure transfers to the underdeveloped word are therefore in the interest of leading countries, and constitute an instrument for global prosperity and peace.

The rest of the chapter is organized as follows. Section 2 presents a concise, simple economic model defining a dynamic human development trap which is then interacted with economic growth. The results are summarized verbally. Then, the world growth rate, and the effects of opening to globalization, particularly on the poor, are discussed. Section 3 concludes.

\section{The model}

Our discussion in the section on human development leads to the following stylized facts about long-term human development. First, technological improvements lead to technophysio evolution; improvements in stature, health and longevity. Second, higher human development provides inputs for raising technological levels. Third, the presence of market failures inhibits the human capital investment that each new generation must make to achieve current levels of human development; only the wealthier part of the population may reach the human development potential that is currently possible, while the poorer part may remain trapped away from achieving its full potential. Here we formalize these ideas in a concise economic model of a human development trap and its interaction with economic growth.

A classical example of a static human capital trap is provided by Galor and Zeira (1993). This trap is based on the need for an indivisible investment for acquiring skills, and on the presence of a credit constraint not allowing the poor to make the investment. I take this model, as presented in Basu (2003, section 3.4), as point of reference to construct a dynamic human development trap model. 


\subsection{The human development trap model}

This section of the model appears in Mayer-Foulkes (2007). Thus here only the necessary elements to understand it are included. Consider an economy with $S_{t}$ skilled workers, each with human capital $A_{t}$, so that the aggregate human capital stock is $H_{t}=A_{t} S_{t}$, and with $L_{t}$ unskilled workers. A single good is produced according to the production function $Y_{t}=$ $\Phi\left(A_{t} L_{t}\right)^{\beta} H_{t}^{1-\beta}=\Phi A_{t} L_{t}^{\beta} S_{t}^{1-\beta}$, with technology level also $A_{t} . \Phi$ is a fixed productivity effect. Wage rates for labor and human capital are therefore given by $w_{t}^{L}=\beta \Phi A_{t}\left(S_{t} / L_{t}\right)^{1-\beta}$ and $w_{t}^{S}=(1-\beta) \Phi A_{t}\left(L_{t} / S_{t}\right)^{\beta}$, and are proportional to $A_{t}$. Note that increasing returns to human capital are not assumed in the model. Instead, what is assumed is that an undersupply of human capital, which will result from barriers to its acquisition, results in a higher, endogenous wage gap between skilled and unskilled wages.

In period $t$, each young person receives a bequest $x_{t}$, and decides whether to invest $h A_{t}$ units in acquiring an indivisible package of $A_{t+1}$ units of human capital consisting of ECD, health and education ("becoming skilled"). ${ }^{13}$ The alternative is to work earning $\eta w_{t}^{L}$, where $0<\eta \leq 1$ represents the ratio of child to adult wages. Any remaining bequest is saved and earns an interest rate $r$. For simplicity, a the credit market is assumed to be missing: it is impossible to borrow to acquire nutrition, health and education. In the second period of life, each adult earns $y_{t+1}$, the sum of her skilled or unskilled wage $\left(w_{t+1}^{S}\right.$ or $\left.w_{t+1}^{L}\right)$ and accrued savings. Each adult consumes $c_{t+1}$ and decides on a bequest $b_{t+1}$ to her one child. Young people maximize:

$$
\max U_{t}=c_{t+1}^{\alpha} b_{t+1}^{1-\alpha}+\delta_{t} u^{H} A_{t}, 0<\alpha<1,
$$

subject to the budget constraint $c_{t+1}+b_{t+1}=y_{t+1}$. The utility function contains two terms. The first represents preferences over consumption and bequests. The second term represents the non-labor benefits of acquiring health and education. $\delta_{t}$ takes the value 1 if skills and health capital were acquired, and 0 otherwise, while $u^{H} A_{t}$ (with $u^{H}$ constant) measures the nonlabor benefits of human capital. For simplicity, so as not to include consumption in both periods to define a discount rate, the interest rate is assumed to be exogenous.

\footnotetext{
${ }^{13}$ I assume technological change transforms both production and human capital. Thus, $A_{t}$ units of human capital acquired in youth become $A_{t+1}$ units of adult human capital. Alternatively, let the package of $A_{t+1}$ units of human capital available to the young cost $h A_{t+1}$, and substitute $h$ with $h g_{t+1}$ in the results.
} 
Assume that the model parameters are such that 1) independently of the ratio $S_{t} / L_{t}$ of skilled to unskilled workers, anybody receiving a bequest $x_{t} \geq A_{t} h$ will decide to acquire human capital; 2) given a technological level $A_{t}$, skilled workers's children can acquire skills and human development; 3 ) the maximum feasible level of human development is bounded.

For now, suppose that the rate of technological change $A_{t+1} / A_{t}=1+g_{t}$ is constant and exogenous, and define the deflated variable $\tilde{x}_{t}=x_{t} / A_{t}$.

Proposition 1. Under these assumptions, a higher steady state $\tilde{x}^{\text {High }}$ in which skills are acquired exists. A lower steady state $\tilde{x}^{\text {Low }}$ in which skills are not acquired also exists (see Figure 1) if the skilled to unskilled workers ratio lies below the critical level

$$
\frac{S_{t}}{L_{t}}<\eta_{\mathrm{Crit}} \equiv\left(\frac{\left(1+g_{t}-(1-\alpha)(1+r)\right) h}{\beta(1-\alpha) \Phi\left(\eta(1+r)+1+g_{t}\right)}\right)^{\frac{1}{1-\beta}}
$$

In this case $S_{t}$ and $L_{t}$ remain constant. For higher growth rates $g_{t}$, higher skilled to unskilled ratios are necessary to escape the trap, and returns to education are higher.

Figure 1 about here

The proof is in Mayer-Foulkes (2007), Appendix A. At both steady states, wages rise with the technological level $A_{t}$, implying growing levels of nutrition and health even for the unskilled. However, the unskilled population is trapped away from reaching the full current human development potential, which is only accessible at the higher steady state. In this sense, the model defines a dynamic poverty trap. The rising indivisible human capital investment models successive investments at different stages of development, such as adequate nutrition, literacy, primary school, secondary school, higher education, and so on, as mentioned above.

As long as the trap exists, children would like to borrow to acquire human capital. Thus, investing in human capital offers higher returns than the interest rate, that is, extraordinary returns to investment.

Define the human resources level

$$
H R_{t}=L_{t}^{\beta} S_{t}^{1-\beta}
$$


In the absence of a trap, all workers are skilled and wages for skilled and unskilled labor will equalize $\left(w_{t}^{L}=w_{t}^{S}\right)$. Skilled and unskilled jobs will be allocated in the ratio $S_{t} / L_{t}=(1-\beta) / \beta$. If the population numbers $N_{t}=S_{t}+L_{t}$, then $H R_{t}=L_{t}^{\beta} S_{t}^{1-\beta}=\beta^{\beta}(1-\beta)^{1-\beta} N_{t}$. This is the optimal level for $H R_{t}$ and its higher bound. Instead, when a human development trap holds, $H R_{t}$ will be lower and production less efficient.

If the dynamic trap condition (1) does not hold, a prolonged transition may nevertheless take place, in which several generations must pass before the offspring of a poor dynasty achieve the full human development potential. Under a prolonged transition, incomplete markets slow the transition to a steady state through prolonged, systematic, under investment in human capital. A transition under perfect markets would be faster.

\subsection{Endogenous technological change}

A simple equation for endogenous technological change is now stated. ${ }^{14}$ For an open economy, set an endogenous rate of technological change

$$
1+g_{t}=\frac{A_{t+1}}{A_{t}}=\left(\frac{\phi Y_{t}^{\mathrm{World}}}{A_{t}}\right)^{\gamma}\left(\frac{\theta Y_{t}}{\bar{\theta}_{\text {World }} Y_{t}^{\mathrm{World}}}\right)^{\kappa} \exp \left(\chi^{\mathrm{FT}}-\frac{A_{t}}{\bar{A}_{t}}\right) .
$$

The first entry expresses that firms innovate more the higher their level of production. It is assumed here that firms serve a demand proportional to the world product, and that they innovate with certainty. Division by $A_{t}$ accounts for the fishing out effect: innovation at higher technological levels is proportionally harder. $\phi$ is a constant including the propensity with which income is invested in innovation, depending for example on institutional arrangements. Decreasing returns to innovation investment in each given sector is assumed, so $0<\gamma<1$. $^{15}$

The second entry expresses the impact of innovation allocation across countries. Countries innovate on the sectors they produce for, whose measure is proportional to their productive capacity. We let proportionality depend on a fixed country effect $\theta$ for country factors that may affect innovation races, and the corresponding average world parameter $\bar{\theta}^{\text {World }}$. Also,

\footnotetext{
${ }^{14}$ Extended versions of this model are available in Mayer-Foulkes (2006a, 2006b).

${ }^{15}$ Note that under this simple specification the returns to innovation are unbounded. It will follow that the scale of resources applied to innovation has an unbounded effect on growth. However, under a more complex, bounded specification, the scale effect would be bounded as well.
} 
there are innovation externalities between sectors. The more sectors a country innovates in, the higher the returns for innovation in each sector. This means that specialization in a small number of sectors involves a disadvantage. This assumption is especially credible in the case of a long-term model. The degree of cross-sectoral externalities in innovation is given by $\kappa$. Externalities are absent if $\kappa=0$; in this case knowledge for production can be completely specialized and a country needs no knowledge about sectors it does not produce for. In the case $\kappa=1$, aggregate technological change equals average technological change in all sectors. This would be the case if knowledge worked through a local leading technological edge resulting from externalities from local innovation. It is assumed that $\kappa$ lies somewhere in between. In fact, it is assumed that $\gamma<\kappa<1$, that is, that decreasing returns to specialization hold, even in the presence of convergence forces. That is, the negative effects, for backward economies, of investing their innovation in a small segment of sectors will be stronger than the advantage of backwardness due to convergence.

In the third entry, $\bar{A}_{t}$ is the leading technological edge, assumed here to be generated in some other country or countries. Thus the economy we are concerned with is a small, lagging country. Technology is assumed to rise faster for lower relative technological levels $a_{t}=A_{t} / \bar{A}_{t}$, due to technology transfer from leading countries, an advantage of backwardness effect generating convergence (Gerschenkron, 1952). The functional form chosen here assumes the convergence effect is bounded by $\exp \left(\chi^{\mathrm{FT}}\right)$ as $a_{t}$ becomes small. This makes divergence in growth rates possible under autarchy.

Under autarchy, the same equation is assumed to hold, with $Y_{t}^{\text {World }}$ replaced by $Y_{t}$ and $\bar{\theta}^{\text {World }}$ by $\theta$. Hence

$$
1+g_{t}=\frac{A_{t+1}}{A_{t}}=\left(\frac{\phi Y_{t}}{A_{t}}\right)^{\gamma} \exp \left(\chi^{\mathrm{A}}-\frac{A_{t}}{\bar{A}_{t}}\right) .
$$

It is reasonable to assume $\chi^{\mathrm{A}}<\chi^{\mathrm{FT}}$, i.e. that technology transfer works less strongly under autarchy than under free trade, when not only ideas but also goods travel between countries. Also, in the presence of comparative advantage (Mayer-Foulkes, 2006a), it can be assumed that the fixed country productivity effects are higher under free trade than under autarchy, so $\Phi_{\mathrm{A}}<$ $\Phi_{\mathrm{FT}}{ }^{16}$ Let $\lambda=Y_{t}^{\mathrm{World}} / \bar{A}_{t}$ and define $1+\bar{g}=\bar{A}_{t+1} / \bar{A}_{t}$.

\footnotetext{
${ }^{16}$ It is assumed throughout that a full human development potential is feasible both
} 
Summarizing, technological change is governed by:

$$
\frac{a_{t+1}}{a_{t}}=\left\{\begin{aligned}
H_{\mathrm{FT}}\left(a_{t}\right) & \equiv \frac{1}{1+\bar{g}}\left(\frac{\theta \Phi_{\mathrm{FT}} H R_{t} a_{t}}{\bar{\theta}_{\mathrm{World}} \lambda}\right)^{\kappa}\left(\frac{\phi \lambda}{a_{t}}\right)^{\gamma} \exp \left(\chi_{\mathrm{FT}}-a_{t}\right) \\
H_{\mathrm{A}}\left(a_{t}\right) & \equiv \frac{1}{1+\bar{g}}\left(\phi \Phi_{\mathrm{A}} H R_{t}\right)^{\gamma} \exp \left(\chi_{\mathrm{A}}-a_{t}\right)
\end{aligned}\right.
$$

where the human resource level $H R_{t}$ defined by (2) is used. This variable defines a scale effect in the equations governing technological change, depending on effective labor force. A more complete model might also include a higher demand for human capital for innovation than for production.

The steady state found in Proposition 1 extends to a free trade or autarchic steady state in relative technological levels if the relative technological level $a_{t}$ is also at a steady state. There are two types of steady states $a^{*}$. Let $H_{\mathrm{X}}$ represent either $H_{\mathrm{FT}}$ or $H_{\mathrm{FT}}$. The first type of steady state is $a^{*}=0$. This exists if and only if $H_{\mathrm{X}}(0)<1$, because then $\lim _{t \rightarrow \infty} a_{t}=0$. When a lagging country approaches this type of steady state, its growth rate becomes lower than the leading technological edge growth rate:

$$
\lim _{t \rightarrow \infty} \frac{A_{t+1}}{A_{t}}=\lim _{t \rightarrow \infty} \frac{a_{t+1}}{a_{t}} \frac{\bar{A}_{t+1}}{\bar{A}_{t}}=H_{\mathrm{X}}(0)(1+\bar{g})<1+\bar{g} .
$$

The second type of steady state occurs for $0<a^{*} \leq 1$. It exists when $H_{\mathrm{X}}\left(a^{*}\right)=1$. The growth rate is then $1+\bar{g}$, and the economy tends to a fixed technological lag $a^{*}$.

For ease of language, we say that at these two types of steady states technology "diverges in growth rates" or "diverges in levels" (equivalently "converges in growth rates").

In the autarchic case, $H_{\mathrm{A}}\left(a_{t}\right)$ is a decreasing function. At most a single steady state exists. In the case of free trade, the following properties hold.

1) $H_{\mathrm{FT}}\left(a_{t}\right)$ is a quasiconcave function.

2) $H_{\mathrm{FT}}(0)=0$.

3) $H_{\mathrm{FT}}\left(a_{t}\right)$ has a single maximum at $a_{t}=\kappa-\gamma \in(0,1)$.

4) $H_{\mathrm{FT}}$ is increasing in $\phi, \theta / \bar{\theta}^{\text {World }}, \Phi_{\mathrm{FT}}, H R_{t}, \chi_{\mathrm{FT}}$, and decreasing in $\lambda$ and $\bar{g}$.

under autarchy and free trade. However, under extreme conditions of comparative advantage, the full human development potential may only be feasible under free trade, when $\Phi_{\mathrm{A}}<\frac{h}{(1-\alpha) \varepsilon(\beta)}<\Phi_{\mathrm{FT}}$. See condition (??) in Appendix A. 
For the proof of these properties, on which Proposition 2 and its Figures 2 and 3 are based, see Appendix A.

Figures 2 and 3 about here

Proposition 2. Under autarchy (Figure 2), a lagging country has the following steady states, which depend only on its parameters.

A.1 If $H_{\mathrm{A}}(0) \leq 1$, there is divergence in growth rates. The absolute rate of growth tends from below to $\left(\phi \Phi_{\mathrm{A}} H R_{t}\right)^{\gamma} \exp \left(\chi_{\mathrm{A}}\right)<1+\bar{g}$.

A.2 If $H_{\mathrm{A}}(0)>1$ and $H_{\mathrm{A}}(1)<1$ there is a steady state $0<a^{*}<1$ at which the economy diverges in levels, with growth rate $1+\bar{g}$.

A.3 If $H_{\mathrm{A}}(1)>1$, the lagging country will overtake the leaders.

In case A.1, steady state growth rates, and in case A.2, steady state levels, are increasing in the propensity to innovate $\phi$, fixed productivity effects $\Phi_{\mathrm{A}}$, human resources $H R_{t}$, and technology transfer rates as measured by $\chi_{\mathrm{A}}$.

Under free trade (Figure 3), the following dynamic configurations for a lagging country exist. The steady states may depend on initial conditions as well as parameters.

FT.1 If $H_{\mathrm{FT}}(\kappa-\gamma) \leq 1$, the only stable steady state is $a^{*}=0$. The lagging country's growth rate decreases towards 0 . In the special case $H_{\mathrm{FT}}(\kappa-\gamma)=$ 1 there is an unstable steady state $a^{*}=\kappa-\gamma$, from which the economy converges to $a^{*}=0$ under any negative perturbation.

If $H_{\mathrm{FT}}(\kappa-\gamma)>1$, a stable and an unstable steady states $a_{0}^{*}, a_{1}^{*}$, exist, satisfying $0=a_{0}^{*}<a_{1}^{*}<\kappa-\gamma$ and $H_{\mathrm{FT}}\left(a_{0}^{*}\right)=0, H_{\mathrm{FT}}\left(a_{1}^{*}\right)=1, H_{\mathrm{FT}}^{\prime}\left(a_{1}^{*}\right)>0$. Two possibilities arise:

FT.2 $H_{\mathrm{FT}}(1) \leq 1$. A further stable steady state $a_{2}^{*} \in(\kappa-\gamma, 1]$ exists with $H_{\mathrm{FT}}^{\prime}\left(a_{2}^{*}\right)<0$.

FT.3 $H_{\mathrm{FT}}(1)>1$. In this case $H_{\mathrm{FT}}\left(a_{t}\right)>1$ on $\left(a_{1}^{*}, 1\right]$.

For initial values $a_{t_{0}}<a_{1}^{*}$, the lagging country tends to $a_{0}^{*}=0$, where its growth rate descends to 0 . For initial values $a_{t_{0}}>a_{1}^{*}$, in case FT.2 the lagging country tends to $a_{2}^{*}$, where it diverges in levels, with growth rate $1+\bar{g}$. In case FT.3 it overtakes the leading economy. If the lagging country becomes a leader, a new world or leading technological edge growth rate will emerge. 
It follows from property 4) of $H_{\mathrm{FT}}$ that a) the higher the lagging country's propensity for innovation; b) the more sectors it dominates; c) the higher its fixed productivity effects; d) the higher the level of human development the more efficient its allocation between skilled and unskilled labor; and e) the higher the rate of technology transfer, the higher will its rate of technological change be. The larger the world economy or its rate of growth, though, the lower its relative steady state. At steady states divergent in growth rates or levels, these comparative statics translates into growth or level effects.

Note that backward countries may diverge in growth rates under free trade even when they might converge to the leading growth rate under autarchy. At any given level $a_{t}$, the relative growth rate under free trade is higher than under autarchy, $H_{\mathrm{FT}}\left(a_{t}\right) / H_{\mathrm{A}}\left(a_{t}\right)>1$, only if

$$
\frac{Y_{t}}{Y_{t}^{\text {World }}}=\frac{H R_{t} a_{t}}{\lambda}>\left(\frac{\bar{\theta}_{\mathrm{World}}^{\kappa} \Phi_{\mathrm{A}}^{\gamma} \exp \left(\chi_{\mathrm{A}}\right)}{\theta^{\kappa} \Phi_{\mathrm{FT}}^{\kappa} \exp \left(\chi_{\mathrm{FT}}\right)}\right)^{\frac{1}{\kappa-\gamma}}
$$

that is, if the relative size of the aggregate product is high enough. In addition, if the lagging country is good at capturing innovation sectors ( $\theta$ high), enjoys high benefits from comparative advantage $\left(\Phi_{\mathrm{FT}}^{\kappa}\right.$ sufficiently larger than $\left.\Phi_{\mathrm{A}}^{\gamma}\right)$, and if technological transfer under trade is sufficiently high $\left(\chi_{\mathrm{FT}}\right.$ sufficiently larger than $\chi_{\mathrm{A}}$ ), growth will tend to be higher under trade. Policies for human development will raise $H_{t} R_{t}$ and contribute to the viability of growth under free trade.

Promoting exports and technological change, as well as concentrating on comparative advantage (that is, raising $\theta, \chi_{\mathrm{FT}}$ and $\Phi_{\mathrm{FT}}^{\kappa}$ ), also contribute to growth under free trade. Steady state membership also depends on institutional and financial development, which can raise aggregate production.

One defining characteristic of the economic unit whose size is referred to by the model, is that it shares knowledge for production and for skill formation. One policy for breaking the size constraint is therefore knowledge integration. Integration through trade and investment must be complemented by integration in education and technology.

Under autarchy, the behavior of the lagging country only depends on its parameters. Instead, under free trade its initial conditions matter. If they are low enough, a lagging country will diverge in growth rates.

The following corollary restates the results to bring out the role of human development in economic growth and globalization (proof in Appendix A). 
Corollary 3. The following conclusions about globalization and human development hold.

HD.1 If human resources $H R_{t}$ in the lagging country are too low, it will necessarily diverge in growth rates. A minimum level $H R_{t}$ for converging in growth rates under free trade is given by the condition $H_{\mathrm{FT}}(\kappa-\gamma)>1$, or:

$$
\left(\frac{\theta \Phi_{\mathrm{FT}} H R_{t}}{\bar{\theta}_{\mathrm{World}}}\right)^{\kappa}>\frac{(1+\bar{g}) \lambda^{\kappa-\gamma}}{\phi^{\gamma}(\kappa-\gamma)^{\kappa-\gamma} \exp \left(\chi_{\mathrm{FT}}-\kappa+\gamma\right)} .
$$

HD.2 Growth will only be faster under free trade than under autarchy if human resources $H R_{t}$ are sufficiently high, as in (6); otherwise too many innovation sectors will be lost to trading partners.

HD.3 Economic growth performance is better for higher levels of human resources $H R_{t}$. At steady states divergent in growth rates or levels, higher human resources $H R_{t}$ translate into growth or level effects. For higher human resource levels $H R_{t}$, the lagging country is more likely to converge rather than diverge in growth rates, since the threshold level $a_{1}^{*}$ is lower.

HD.4 If a government carries out policies for human capital investment for the children of the unskilled, a steady state can only occur once human resources reach their maximal level $H R_{t}=\beta^{\beta}(1-\beta)^{1-\beta} N_{t}$ and the human development trap has disappeared. Under autarchy, the economy will eventually converge to a steady state diverging in levels only. Under free trade, the feasibility for convergence in growth rates will occur only if from some time on, $a_{t}>a_{1}^{*}$, with $H R_{t}=\beta^{\beta}(1-\beta)^{1-\beta} N_{t}$.

HD.5 An economy converging to $a_{2}^{*}$ will be able to achieve human development. However, human capital equality does not guarantee development.

\subsection{Summary of results}

The propositions concentrate on lagging countries. In the autarchic case, a single stable steady state exists, independently of initial conditions. Country parameters and the level of human development determine whether the lagging country diverges in growth rates, diverges in levels, or overtakes the leading economy. It is assumed that convergence forces are bounded, making divergence possible under autarchy as well.

In the case of free trade, small economies can only innovate in a handful of sectors, with a consequently low rate of technological change. Thus, for low country parameters and/or low levels of human development, divergence in 
growth rates is the only steady state. For higher parameters or levels of human development, lagging economies with sufficiently high initial conditions will either converge in levels or overtake the leading economy.

There is a scale effect inherent in the technological change model. However, this effect is unbounded only for mathematical tractability. If innovation rates are bounded, so will the scale effect. Because of the scale effect, the relevant measure translating human development into growth is human resources, meaning aggregate units of combined skilled and unskilled labor. Under a human development trap, human capital undersupply will reduce aggregate human resources. Human resources affect economic growth under free trade as follows. First, productive efficiency will be higher for higher levels of human resources, increasing resources for innovation. Second, there is a minimum level of human resources needed for convergence in growth rates. If these are too low, the lagging country will necessarily diverge in growth rates. Third, there is also a minimum human resource requirement for growth to be faster under free trade than under autarchy; otherwise too many innovation sectors will be lost to trading partners. Hence, at steady states diverging in growth rates or levels, higher human resources translate to higher growth rates or levels. Fourth, lagging countries are more likely to converge rather than diverge in growth rates for higher levels of human resources. Fifth, a successful development path will be able to achieve human development. On the other hand, since the level of human development depends on the level of technology, equality does not of its own guarantee development.

The presence or absence of government human capital investment raising the skilled to unskilled ratio $S_{t} / L_{t}$ is a condition of the steady state. A human development trap can only exist at steady state if there is no human capital investment for the poor. Conversely, if there is human capital investment, $S_{t} / L_{t}$ will rise until the human development trap disappears before a steady state can be reached. Beginning from low levels of development, even if it is feasible to reach a developed, higher technology steady state, too much or too little investment in human capital may make this impossible. Even if human capital equality is achieved, underdevelopment may persist, with technological levels diverging in levels or growth rates from leading countries. A careful balance is needed between supporting human capital investment - an essential component of growth - and a favorable insertion in globalization, to reach high technological levels. 


\subsection{Optimal world growth rate}

It has been assumed above that only research in leading countries advances the leading technological edge. This is a reasonable assumption for countries lagging sufficiently far behind. However, when countries converge to the leading countries, eventually their research will also push the leading technological edge. In this case, under trade, the world growth rate will rise. Since the leading countries' welfare increases with the world growth rate, convergence of the underdeveloped countries is in their long-term interest. This result is proved formally in Mayer-Foulkes (2006a, 2006b).

\subsection{The impact of opening to globalization}

The liberalization policies applied in Latin America take the form of a transition from an autarchic to an open steady state. This is costly in itself. I discuss here some implications of this process, particularly on poverty.

First, the model predicts dramatic structural economic change, as does any trade model. Many productive sectors will disappear as the economy specializes in its most productive tradeable sectors, which must be competitive in world markets. The expected magnitude of this process of specialization is large for any economy in Latin America. The reason is that the share of world-competitive sectors can at most be proportional to productive capacity and is therefore small. If in practice commercial integration is regional rather than global, less sectors will be lost, but those remaining will have less market power and therefore less incentives for innovation.

The reform process has usually been very fast. Economies have been subjected to a large, multifaceted shock, structured as follows. In non worldcompetitive sectors, capital and human capital loose value and unskilled labor demand falls. In sectors receiving FDI by higher technology foreign firms, competing domestic firms tend to be displaced. Skilled and unskilled labor demand will depend on the specific FDI sectors involved. In worldcompetitive domestic sectors, or in sectors supplying FDI, volume, innovation incentives, and labor demand will tend to increase, with possible bottlenecks in specialized human capital. Summing up, it is likely that there will be a negative initial shock to unskilled wages, with some skilled wages rising. To this must be added a series of transition costs and risks, whose impact can be very high for the poor. It is no surprise that this process of sudden change has given rise to volatility and financial crises. 
This is where the predictions of trade models based on competitive production end. The expected benefits are short- and medium- term gains in comparative advantage, with sketchy links to further economic growth. The present model points out that the longer-term success of opening to trade and FDI depends on the success of innovation in surviving domestic sectors. However, the reforms have not planned for this. Instead, the results have been left "to the market". To be successful, sectors with comparative advantage that have been supplying only the domestic market should now not only preserve this advantage in the face of foreign technological improvement, but grow to become innovative, world suppliers! With little or no investment in public physical, human or research infrastructure, and scant negotiation for spillovers from FDI. Though the future wealth of the population depends on these sectors, these disadvantages and neglect translate into even lower initial conditions.

The panorama of the impact of globalization coincides with the model predictions. Positive and negative impacts are distributed with great variance across sectors, regions and countries. Inequality tends to rise, with increased insecurity and a very real risk of falling into poverty for those employed in unlucky sectors or regions, or those who need to bear the costs of transition or retraining. The poor require safety nets and appropriate social protection schemes. Resulting inequality may lead to conflict and difficulties for growth. Firms in successful sectors may be too small to face the challenge of multinational marketing chains, and obstacles may occur to firm size, an important determinant of world-competitiveness. As successful sectors suddenly require new technologies to increase production, the tendency to use ready-made technologies from abroad suited to higher levels of skills will result in skill-biased technological change and inefficiencies.

\section{Final remarks}

The model presented here explains persistent income inequality between and within countries, compares import substitution and export promotion, and accounts for episodes of miracle growth. It shows that development and underdevelopment can coexist as steady states in the context of globalization.

The results rely on just two types of market imperfections, both of which are commonly accepted facts. Increasing returns to education or in production are not assumed. The first type of imperfection are incomplete markets 
in human capital investment. Children are not endowed by the market with their human capital investment, in spite of its notable returns. Instead, initial conditions in wealth determine the incidence of investment. This problem can result in a human development trap that subdivides the population into classes and can persist under economic growth. Strong evidence for the presence of such a trap in Mexico is provided by Mayer-Foulkes (2007). Surely this is not an isolated phenomenon.

The second type of imperfection is market power derived from innovation. To remove any doubt on the relevance of market power, note that aggregate world exports in 1998 amounted to US $\$ 7$ trillion, while aggregate sales from foreign affiliates of transnational corporations amounted to US $\$ 11$ trillion (UNCTAD, 1999). The combined sales of the top 200 corporations were higher in 2000 than the combined economies of all countries minus the biggest 9; that is, they surpassed the combined economies of 182 countries (Anderson and Cavanagh, 2000). Property rights over innovation, and the resulting market power, are considered a condition for its existence. As has been explained, under free trade the corresponding assumptions in the theory of endogenous technological change, including innovation externalities between sectors, imply the existence of multiple steady states (Mayer-Foulkes, 2006a, $2006 b)$.

The fact that human development and technological change, the main processes of economic growth, are subject to market imperfections, results in the existence of a diverse set of steady states: widely varying incomes and growth rates, episodes of miracle growth (understood as transitions between steady states), economic growth without inequality reduction, positive and negative impacts of trade on growth, convergence to parallel growth paths of a large group of countries, long-term divergence and stagnation, pro-rich and pro-poor policy regimes. Thus the theoretical model explains the broad physiognomy of economic growth.

The idea that under globalization resources will flow so that economies equalize is based on the predominance of competitive markets. If this were the reality, the Great Divergence would not have occurred, and development would have spread equally around the world since its origins. For, what forces could keep competitive markets so out of balance?

Sound global economic policies must recognize the powerful impact of these market imperfections in human development and innovation. Globalization - free trade and FDI - generates innovation imbalances that must be compensated for lagging countries to develop. It is a matter of experience 
that countries that have implemented complementary measures promoting their exports and regulating FDI, so as to develop their technological capabilities, have been able to achieve sustained economic growth for long periods, that is, miracle growth. When this has occurred, as in the case of the Asian tigers and China, both the countries involved and their commercial partners have benefited. Such policies can be implemented by individual countries or regions. However, it would be optimal if they were carried out as an integral part of global governance. The very institutions that regulate trade and investment, WTO, IMF and the World Bank, must commit to balance the incentives for innovation and technological change, to ensure that globalization brings economic development for all.

The model shows that in the presence of a human development trap there is a natural policy conflict between emphasizing human development or technological change. Both extremes have their problems. If only technological change is pursued, the human development trap can persist. From this point of view, the UN Millennium Development Goals are an essential components of economic growth. Instead, if only human capital investment is pursued, the technological lag may become too large for development to be feasible. Eventually a policy change will become inevitable.

Development is not a zero-sum game. It is in the economic interest of leading countries to foster productive and innovative capabilities around the world. The world growth rate is maximal when all countries are developed. Successful technology transfer and adoption will raise economic growth in both lagging and leading countries. In turn, economic growth will increment the incentives and the resources to dismantle the human development trap, liberating vast economic and human potential. Making globalization successful for all will provide a foundation for global peace and prosperity.

\section{Appendix A}

Properties of $H_{\mathrm{FT}}\left(a_{t}\right)$. Observe that the function $f\left(a_{t}\right)=a_{t}^{\kappa-\gamma} \exp \left(1-a_{t}\right)$ satisfies $f(0)=0, f^{\prime}(1)=\kappa-1-\gamma<0$, since $0<\gamma<\kappa<1$. Also, $f\left(a_{t}\right)$ is quasiconcave, since

$$
\frac{d}{d a_{t}} \ln \left(a_{t}^{\kappa-\gamma} \exp \left(1-a_{t}\right)\right)=\frac{d}{d a_{t}}\left((\kappa-\gamma) \ln a_{t}+1-a_{t}\right)=\frac{\kappa-\gamma}{a_{t}}-1
$$

is positive for $a_{t}<\kappa-\gamma$ and negative for $a_{t}>\kappa-\gamma$, with its unique maximum at $\kappa-\gamma$. 
Proof of Corollary 3. Parts 1,2 are proved in their statements. Part 3 follows directly from (5) and the properties of $H_{\mathrm{FT}}\left(a_{t}\right), H_{\mathrm{A}}\left(a_{t}\right)$. Part 4 is evident as follows. So long as there is human capital investment the ratio $S_{t} / L_{t}$ will change. Hence a steady state cannot be reached until the human development trap ceases to exist. Convergence in growth rates (or divergence in levels) means reaching a steady state $a_{2}^{*}$. Since $a_{2}^{*}>a_{1}^{*}$, a converging trajectory must from some time on satisfy this inequality. The first statement in Part 5 follows from noting that at any point in such a trajectory $a_{t}$ some finite proportion of income can be invested in human capital without compromising $a_{t}>a_{1}^{*}$. Under this condition achieving human development takes finite time. On the other hand, human capital equality, or equivalently human development, is also possible at a lower, divergent, steady state.

\section{$5 \quad$ References}

Acemoglu, Daron, Philippe Aghion, and Fabrizio Zilibotti. "Distance to Frontier, Selection and Economic Growth." NBER Working Paper 9066, July 2002.

Aghion, P. and Howitt, P. (1988). "Growth and Cycles through Creative Destruction". MIT Mimeo.

Aghion, P. and Howitt, P. (1992). "A Model of Growth through Creative Destruction". Econometrica 60:323-51.

Aghion, P.; Howitt, P.; and Mayer-Foulkes, D. (2005). "The Effect of Financial Development on Convergence: Theory and Evidence", Quarterly Journal of Economics, vol. 120, issue 1, Feb.

Anderson, Sarah and Cavanagh, John (2000). Top 200: "The Rise of Global Corporate Power" Corporate Watch, http://www.globalpolicy.org/socecon/tncs/top200.htm.

Birdsall, N., Ross, D., \& Sabot, R. (1997). Education, Growth and Inequality. In N. Birdsall, \& F. Jaspersen (Eds.), Pathways to Growth: Comparing East Asia and Latin America. Washington, DC: Inter-American Development Bank.

Case, Anne; Fertig, Angela and Paxson, Christina (2003). "From Cradle to Grave? The lasting impact of childhood health and circumstance". 
National Bureau of Economic Research, NBER Working Paper 9788, Cambridge, Massachusetts.

Cervellati, Matteo and Uwe Sunde. (2003). "Human Capital formation, Life Expectancy and the Process of Economic Development", mimeo.

Cohen, Wesley M., and Daniel A. Levinthal. "Innovation and Learning: The Two Faces of R\&D." Economic Journal 99 (September 1989): 569-96.

Evans, Paul. "Using Cross-Country Variances to Evaluate Growth Theories." Journal of Economic Dynamics and Control 20 (June-July 1996): 1027-49.

Fogel, R. W. (2002). "Nutrition, Physiological Capital, and Economic Growth", Pan American Health Organization and Inter-American Development Bank, available at http://www.paho.org/English/HDP/HDD/fogel.pdf

Galor, O. and Zeira, J (1993), "Income Distribution and Macroeconomics", Review of Economic Studies,60, 35-52.

Gerschenkron, Alexander. (1952) Economic Backwardness in Historical Perspective. In The Progress of Underdeveloped Areas, edited by Bert F. Hoselitz. Chicago: University of Chicago Press.

Griffith, Rachel, Stephen Redding, and John Van Reenen. "Mapping the Two Faces of R\&D: Productivity Growth in a Panel of OECD Industries." unpublished, August 2001.

Heckman, J. \& Carneiro, P. (2003). Human Capital Policy. NBER Working Paper 9495. Cambridge, MA: National Bureau of Economic Research.

Howitt, Peter. (2000) "Endogenous Growth and Cross-Country Income Differences." American Economic Review,90, 829-46.

Howitt, P. and Mayer-Foulkes, D. (2005). "R\&D, Implementation and Stagnation: A Schumpeterian Theory of Convergence Clubs", Journal of Money, Credit and Banking, Vol. 37, No. 1, Feb.

ILO (2000). The social and labour impact of globalization in the manufacture of transport equipment, Report for discussion at the Tripartite Meeting on the Social and Labour Impact of Globalization in the Manufacture of Transport Equipment. Geneva, 8 - 12 May 2000. International Labour Office, Geneva.

Kanbur, R. (2005). "Growth Inequality And Poverty: Some Hard Questions" Journal of International Affairs, Spring, vol. 58, no. 2.

Jamison, D. (1986). Child malnutrition and school performance in China. Journal of Development Economics, 20, 299-309.

Keller, Wolfgang (2004), "International Technology Diffusion," Journal of Economic Literature, forthcoming. 
Maddison, A. (2001). The World Economy: A Millennial Perspective. Development Centre Studies. Paris: OECD.

Mayer-Foulkes (2003). "Convergence Clubs in Cross-Country Life Expectancy Dynamics", in Perspectives on Growth and Poverty, Rolph van der Hoeven and Antony Shorrocks (editors), United Nations University Press, 2003, pp. 144-171.

Mayer-Foulkes, D. (2005). "Human Development Traps and Economic Growth", in Health and Economic Growth: Findings and Policy Implications, edited by Guillem López-Casasnovas, Berta Rivera and Luis Currais, MIT Press.

Mayer-Foulkes, D. (2006a). "Development and Underdevelopment: 15002000". Mimeo.

Mayer-Foulkes, D. (2006b). "The Impact of Free Trade and FDI: Banana Republic or Miracle Growth?". Mimeo.

Mayer-Foulkes, D. (2007). "The Human Development Trap in Mexico". Forthcoming in World Development.

Pritchett, L. (1997). Divergence, Big Time. Journal of Economic Perspectives 11(3): 3-17.

Rodriguez and Rodrik (1999). "Trade Policy and Economic Growth: A Skeptic's Guide to Cross-National Evidence", NBER Working Paper No. 7081

Rodrik, Dani (2005). "Growth Strategies," in: Philippe Aghion \& Steven Durlauf (ed.), Handbook of Economic Growth, edition 1, volume 1, chapter 14, pages 967-1014, Elsevier.

UNCTAD (1999). World Investment Report 1999. United Nations, New York.

Wan Jr., H. Y. (2004). Economic Development in a Globalized Environment: East Asian Evidences. Kluwer Academic Publishers, The Netherlands. 


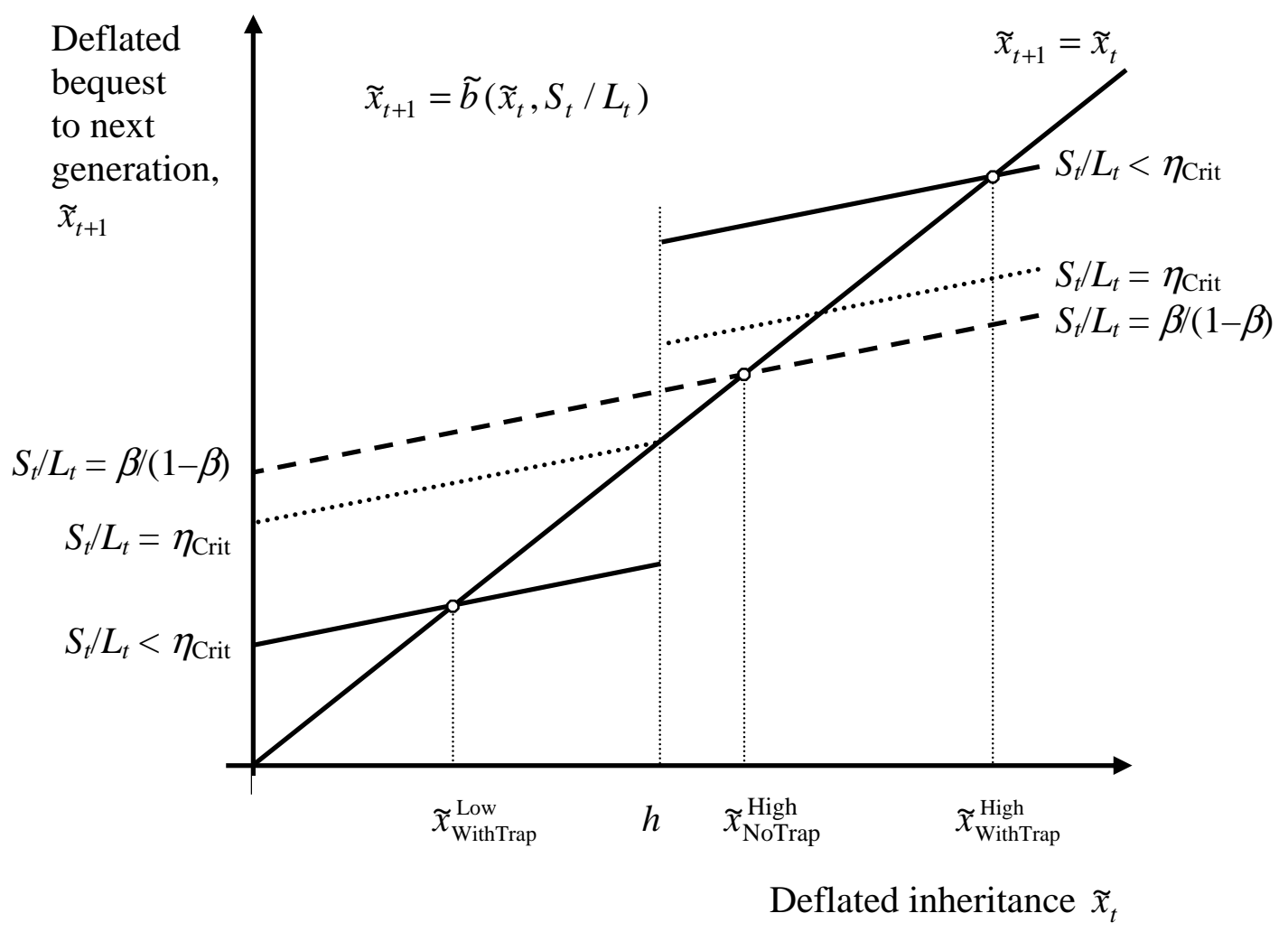

Figure 1. Dynamic Human Development Trap. Children who inherit more than $h A_{t}$ (deflated to $h$ ) chose to be skilled. They earn higher wages and bequest more to their children. Wages for skilled and unskilled workers are endogenous and depend on the aggregate ratio of skilled to unskilled workers $S_{t} / L_{t}$. If this ratio lies below the critical level $\eta_{\text {Crit, }}$ there is a trap, which otherwise disappears. Near the critical level $\eta_{\text {Crit, }}$ workers receiving bequests below $h A_{t}$ will go through a prolonged transition towards the higher steady state. Human development is “viable and bounded" when steady state $\widetilde{x}_{\text {NoTrap }}^{\text {High }}$ exists. 


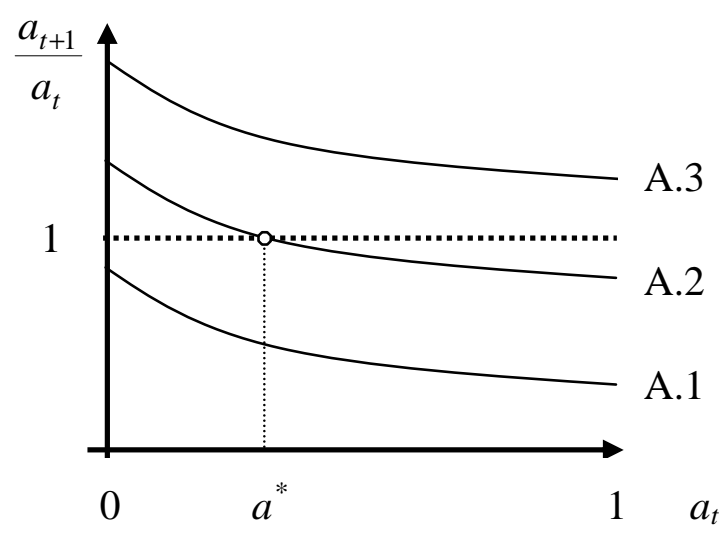

Figure 2. Dynamics of Technological Change under Autarchy. The diagram shows the three cases that arise for the case of autarchy in Proposition 2: A.1, A.2 and A.3.

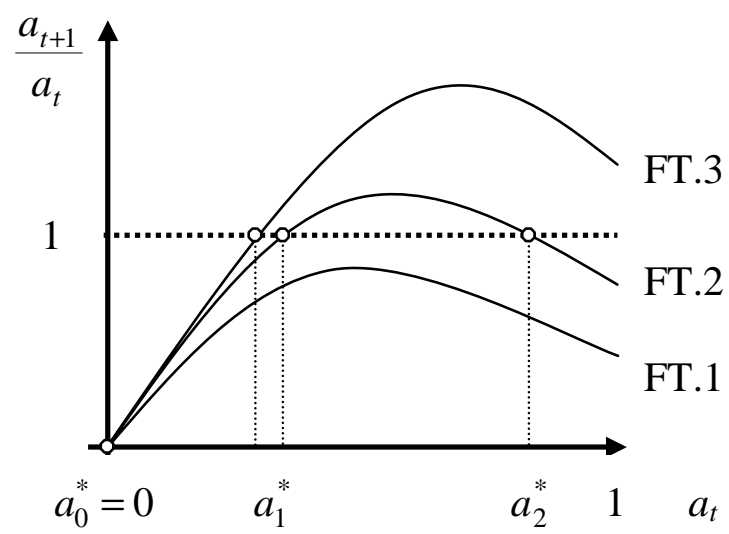

Figure 3. Dynamics of Technological Change under Free Trade. The diagram shows the three cases that arise for the case of free trade in Proposition 2: FT.1, FT.2 and FT.3. 